\title{
DEBATES
}

\section{Os limites da agenda-setting na popularidade do presidente: consumo de notícias e escolaridade na avaliação do governo Dilma Rousseff (2013)}

\author{
Limits of the agenda-setting in the popularity of president: news \\ consumption and education in assessing the government Dilma Rousseff \\ (2013)
}

\section{Helcimara Telles \\ Thiago Sampaio Érica Baptista}

\begin{abstract}
Resumo
Os presidentes são avaliados pela capacidade de solucionar problemas nacionais. Aqui analisamos em que medida a compreensão dos cidadãos sobre as questóes políticas do país sofre influência da mídia. O objetivo é verificar como os hábitos de informação e a percepçáo acerca dos problemas nacionais se diversificam e afetam a leitura da população sobre as ações desenvolvidas pelo presidente. Dessa forma, nos detemos sobre os efeitos desses fatores na identificação dos problemas nacionais e na avaliaçáo do governo da presidente Dilma Rousseff, em 2013. A hipótese é a de que o consumo de mídia tem capacidade limitada para interferir na avaliação de governo, uma vez que ela é definida por predisposiçóes. A escolaridade e a renda influenciam as plataformas midiáticas selecionadas pelos cidadãos e são variáveis mais adequadas para entender a exposição aos meios de comunicação e a avaliação de governo do que a Teoria da Agenda-Setting. A análise contou com dados da Pesquisa Brasileira de Mídia 2013 (BRASIL, 2014).
\end{abstract}

\section{Palavras-chave}

Avaliação de Governo; Consumo de Mídia; Agenda-Setting; Educação.

\begin{abstract}
Presidents are evaluated for their ability to solve national problems. Here we analyze to what extent the understanding of people about the country's political issues is influenced by the media. The aim is to verify how the information habits and attention to national problems diversify and affect the public reading about the actions taken by the President. Our hypothesis is that media consumption has limited capacity to interfere in the evaluation of government, since it is defined by predispositions. Schooling and income define media platforms to which citizens are exposed and are more appropriate variables to understand the exposure to the media and evaluation of government that the theory of agenda-setting. Thus, we retain the effects of these factors in the identification of national problems and the popularity of President Dilma Rousseff. The analysis has used data from the "Pesquisa Brasileira de Mídia" 2013 (BRASIL, 2014).
\end{abstract}

\section{Keywords}

Government Assessment; Media Consumption; Agenda Setting; Education. 


\section{Introdução ${ }^{1}$}

Inúmeros estudos, realizados sobretudo a partir dos anos 1970, buscam demonstrar como se estrutura a popularidade do governo (GOODHART e BHANSALI, 1970; MUELLER, 1970; KRAMER, 1971). A popularidade do governo faz parte de um conjunto de elementos e estes são essenciais para garantir a governabilidade. Presidentes populares possuem prestígio perante as lideranças políticas, mídia e opinião pública (NEUSTADT, 1980; RIVERS e ROSE, 1985). Tal prestígio amplia a autonomia do presidente sobre a agenda governamental e reduz a necessidade de longas negociaçóes para que as decisões do governo sejam efetivadas (EDWARDS, 1980). Ao ter a aprovação dos eleitores, o apoio de políticos e burocratas aumenta e, consequentemente, sáo reduzidas as barreiras para a imposição da agenda política. Por outro lado, com baixo apoio popular, o governo vê a sua capacidade de ação diminuir pari passu ao fortalecimento da oposição e ao crescimento da fiscalização sobre suas açôes. Nesse cenário, é necessário maior esforço para o governo implementar políticas e construir alianças (RIVERS e ROSE, 1985).

Diante disso, compreender como o governo é avaliado pelos eleitores importa, já que a aprovação positiva facilita a atuação do governante, possibilitando a execuçáo de políticas adequadas às demandas da população que, por sua vez, favorece a ampliação da popularidade do presidente (NEUSTADT, 1980). Os principais fatores que afetam a popularidade do governo estáo relacionados a aspectos sociais, políticos e econômicos (ERIKSON, MACKUEN e STIMSON, 2002). A interpretação dos eleitores sobre tais fatores sofre a influência de elementos como a percepção individual, as predisposições políticas e a mídia (BRODY, 1991; TELLES, SAMPAIO e BAPTISTA, 2014). Isto é, a compreensão acerca dos fatos cotidianos tende a direcionar a atenção sobre questões políticas veiculadas pela mídia. A situação econômica pessoal, bem como a escolaridade, também são fatores que podem afetar as atitudes políticas dos cidadãos e, consequentemente, as maneiras como avaliam o desempenho do governo.

Diante disso, aqui temos como objetivo compreender a relação existente entre o consumo de mídia - da plataforma e não do conteúdo -, e a percepção que os eleitores mantêm sobre a atuaçáo do presidente. A percepção sobre o mandato - se positiva ou negativa -, formula a popularidade do governo. Nesse sentido, analisamos

\footnotetext{
${ }^{1}$ Este artigo é uma versão revisada do apresentado em mesas redondas no Encontro da Associação Brasileira de Ciência Política (ABCP), Brasília, julho de 2014, e na Associação Nacional de PósGraduação em Ciências Sociais (ANPOCS), Caxambu, outubro de 2014. Agradecemos aos pareceristas anônimos pelas preciosas sugestôes ao artigo, que foram em parte incorporadas a esta versão.
} 
em que medida o consumo de notícias, os hábitos de informação, a exposição a programas de naturezas distintas, a escolaridade e a renda influenciam o julgamento dos cidadáos acerca do desempenho do governo e a popularidade do governo. Assim, cabe aqui, em primeiro lugar analisar qual o perfil do público brasileiro que utiliza os veículos de comunicação para se informar sobre questóes políticas e econômicas e, em seguida, verificar se há relação entre o acesso ao noticiário e a avaliação dos eleitores sobre o governo da presidente Dilma Rousseff. Vale destacar que nossa análise considera, principalmente, o tempo que os indivíduos dedicam aos veículos de comunicação. Acreditamos que o tempo de exposição será significativo para compreendermos o papel de cada veículo².

Neste artigo náo se pretende investigar "como" os sujeitos formam a sua opinião nem se estender sobre todas as possibilidades que atuam para desenvolver a posição e as atitudes políticas e avaliativas dos cidadãos. Este debate, que tem origem nas correntes que se dedicam ao comportamento político e ao papel dos meios de comunicação nas atitudes políticas, é realizado desde os anos 1950, na literatura nacional e internacional, e já rendeu inúmeras polêmicas sobre o peso da mídia na formação da opinião pública, bem como sobre se os seus efeitos seriam limitados ou ilimitados.

Nossa reflexão também não analisa o conteúdo e o enquadramento das notícias, como feitos pelos estudos de recepção. Para isso, seriam necessários outros tipos de dados e de desenho de pesquisa. Os estudos de recepçáo mostraram que existem inúmeros fatores que interferem na relação entre os cidadãos e os meios de comunicação e, consequentemente, nas interpretações que os cidadáos possuem sobre qualquer tema, inclusive a política. Estes fatores vão desde as formas de socialização, a experiência individual vivida, passam pelas influências de outros atores sociais, até chegar à ideologia propriamente dita.

Além disso, não se pode interpretar a formaçáo das posiçôes políticas dos indivíduos exclusivamente a partir da conexão estabelecida entre a mídia e o cidadão, visto apenas como consumidor de produtos midiáticos. Os conteúdos produzidos e veiculados na mídia são feitos por cidadãos-emissores que se dirigem a cidadãosreceptores em diferentes níveis de interação. Existe uma "elite cognitiva" formada por jornalistas, apresentadores de TV e outros, responsáveis pela organização das narrativas da política, que tendem a orientar as interpretaçôes da audiência (ALDÉ, 2004).

\footnotetext{
2 Análises posteriores poderão identificar, dentro de cada veículo, quais conteúdos são mais significativos para alterar a percepção dos eleitores sobre o governo.
} 
Nosso objetivo é o de dialogar com os discursos e estudos que consideram apenas a relação direta entre a mídia e a opinião pública (grande parte dos estudos de agenda-setting), para inserir um elemento fundamental na explicação da avaliação de governo, que é a educação e/ou renda. Surge a partir desta associação, clara polarizaçáo em torno da mídia. Essa polarizaçáo irá afetar na percepção sobre quais problemas nacionais são mais relevantes. Assim, é preciso observar quais os veículos de preferência dos apoiadores e opositores da presidente, qual o tempo que eles dispensam no consumo de informaçóes e qual a importância dada a notícias sobre o governo.

Do ponto de vista teórico, inúmeras interferências podem afetar a popularidade do governo, como as predisposiçóes ideológicas, os valores, a identidade partidária, a economia e, mesmo, as emoçóes e sentimentos em relação aos governos. Tais predisposiçôes antecedem e interagem com as escolhas dos meios de comunicação que os cidadãos selecionam para se exporem e se informarem, bem como influenciam na avaliação de governo. Contudo, este artigo pretende especialmente verificar se um destes fatores - escolaridade e renda - atua sobre o consumo de mídias e, ainda, averiguar se a avaliaçáo e consequente popularidade do governo da presidente Dilma Rousseff variou em 2013, conforme a renda e escolaridade.

Nossa hipótese teórica é a de que o consumo de mídia tem capacidade limitada para interferir na avaliaçáo de governo. A escolaridade e a renda definem as plataformas midiáticas às quais os cidadáos serão expostos e são variáveis mais adequadas para entender a popularidade de governo do que a teoria da agenda-setting. Neste sentido, os efeitos da mídia são limitados: como a escolaridade é variável de longo prazo e consumo de mídia é de curto prazo, a primeira antecede a segunda. As pessoas são escolarizadas e depois consomem mídia e não se escolarizam mais porque consomem mais mídia.

Para análise dessas questóes, nos amparamos na Pesquisa Brasileira de Mídia 2013 (PBM) (BRASIL, 2014), que foi realizada entre 12 de outubro e 6 de novembro de 2013, pela Secretaria de Comunicação Social da Presidência da República (SECOM), com um universo de 18.312 entrevistados em 848 municípios, distribuídos em todo país; a margem de erro estimada foi de 1 ponto percentual para mais ou para menos, assumindo-se o intervalo de confiança de $95 \%$.

Dado às características desta pesquisa, nossas variáveis de controle são limitadas. Primeiro, porque inúmeras variáveis políticas que poderiam ser controladas por avaliação de governo - como as citadas e mesmo a preferência partidária -, não poderão ser utilizadas em nosso modelo, pois não existiam nos questionários. E, em segundo lugar, a comparação seria melhor se fosse realizada não com as plataformas, 
mas com os conteúdos emitidos, uma vez que o público que acessa um meio de comunicação pode ter suas opinióes afetadas não por estar exposto a tal meio, mas pelos conteúdos por ele transmitido, e tal conteúdo interferir na avaliação do governo. O problema é que a Pesquisa Brasileira de Mídia não identifica conteúdo, apenas o volume de consumo de mídia. Finalmente, tomamos os dados apenas da pesquisa de 2013 (BRASIL, 2014), que são afetados por uma determinada conjuntura política e são insuficientes para generalizações. Ainda com estes limites, julgamos relevante debruçar sobre os dados desta pesquisa, que nos fornece subsídios para ponderarmos sobre os efeitos do consumo de mídia na avaliaçáo do governo Dilma Rousseff, em 2013, que corresponde ao segundo ano do seu mandato.

\section{Opinião pública e os media effects sobre a imagem do presidente}

Quando se analisa os fatos que interferem na popularidade de um político e na avaliaçáo do desempenho de um governo, trata-se de interpretar como se forma a opiniáo pública e qual os efeitos que a mídia pode ter sobre ela - se os efeitos são limitados ou ilimitados. A opinião pública se constitui a partir de valores e atitudes majoritárias, sendo produto de um processo coletivo, no qual atuam diversos atores sociais, com maior ou menor grau de relevância. Observa-se na formação da opinião pública, o entrecruzamento de conhecimento e as crenças, de um lado, e das opinióes e apreciaçóes, de outro (CHAMPAGNE, 1998; DA VIÁ, 1983; CHARAUDEAU, 2005; EMEDIATO, 2013).

A opinião pública se forma a partir de um processo de interação, inicialmente entre grupos primários até chegar aos grandes grupos. Crespi (2000) propóe que o processo da opiniáo seria um modelo de cascata, de modo que uma série de processos descendentes culmina com a chegada da opiniáo ao "grande público", que pouco influencia no processo da formação da opiniâo desde os níveis superiores. Dessa forma, pode se entender que a opinião não é imposta pelo público, mas ao público. Ainda que as propostas de modelos de formação da opinião pública sejam diferentes em sua estrutura, elas concordam em admitir que se trata de um processo coletivo.

Se as opiniōes são resultantes de um ou vários processos de formação, a mídia compóe esse processo ao mediar as informaçóes entre os debates que são realizados entre atores sociais e o público, de modo que o público tenha mais instrumentos para definir sua opiniáo diante do debate posto (LIPPMANN, 1965; BERGER e LUCKMANN, 2003). A mídia compila e hierarquiza os acontecimentos que devemos conhecer, de modo a nos situar no mundo. Os graus de influência dos meios de comunicação são limitados e devem ser observados em função do tempo, ou 
seja, a maior ou menor possibilidade de influência da mídia sobre a opinião pública pode variar de acordo com momentos mais ou menos críticos da sociedade (MCQUAIL, 1996). Em tempos de crise, sejam políticas ou econômicas, a mídia parece ser mais influente, uma vez que a situação da economia é um elemento fundamental na avaliação de governo e também porque atalhos cognitivos que dáo estabilidade à opinião pública, como partidos políticos, tendem a ser desgastados em períodos de crises políticas. E, sem a confiança nas informaçóes produzidas por este ator, o público acaba por dar mais credibilidade à cobertura realizada pela mídia.

$\mathrm{Na}$ contemporaneidade, os meios de comunicação de massa têm peso essencial na política dos países democráticos. Isso porque não apenas informam os cidadãos a respeito das açôes do Estado, como participam da formação da opinião pública. Além disso, também atuam como vigilantes do poder público e das elites políticas - a mídia enquanto cão de guarda, como propóe a literatura norteamericana (GUREVITCH e BLUMLER, 2002). No sistema democrático, os meios de comunicação formam uma estrutura policêntrica que sofre o contrapeso da polifonia de mensagens. $\mathrm{O}$ que não ocorre em um sistema totalitário, no qual a mídia é monocêntrica. Tendo em vista essa centralidade da mídia nas sociedades contemporâneas, e partindo de uma hipótese teórica geral de que ela influencia a opiniâo pública, questiona-se, portanto, em que medida e quais os efeitos dessa influência sobre indivíduos, grupos e sobre o sistema social como um todo. E para tanto, recorrem-se a algumas hipóteses como a de agendamento, enquadramento e do priming midiático.

De acordo com a hipótese de agenda-setting, a mídia seria capaz de redirecionar a atenção do público a determinados temas tidos como de "maior interesse" (PARK, 1925; LONG, 1958; MCCOMBS e SHAW, 1972; LIPPMANN, 1965). O agendamento é feito quando se escolhe priorizar determinados temas e ofuscar, ou mesmo ignorar, outros. De acordo com essa abordagem, a mídia não teria capacidade de dizer às pessoas o que pensar, porém seria possível dizer sobre o que elas deveriam pensar. A mídia oferece pistas de temas relevantes ao público, organiza sua própria agenda e decide quais são os assuntos importantes que devem ocupar o debate público. A hipótese do agendamento da mídia sugere que a agenda dos meios de comunicação é revertida em agenda da opinião pública (IYENGAR, PETERS e KINDER, 1982). E, nesse sentido, pode-se questionar quais temas são mais recorrentes nos meios de comunicação e se eles refletem, de alguma forma, na agenda da opinião pública.

Outra hipótese de influência midiática diz respeito ao priming, que é compreendido como a continuidade do agendamento e discute como determinados 
esquemas mentais são ativados pelo conteúdo das notícias, e como isso pode afetar a manutenção ou a mudança das avaliaçóes do público sobre determinados temas ou atores políticos (IYENGAR e KINDER, 2010; WEAVER, 2007). Para esta hipótese, a variável independente é a descrição que um acontecimento recebe pela mídia, ao passo que a variável dependente é a avaliação que as pessoas fazem dos temas ou atores políticos apresentados pela mídia (CHONG e DRUKMAN, 2007). Cabe esclarecer que a agenda-setting se ocupa dos acontecimentos selecionados pela mídia para conduzirem o debate público, ao passo que o priming diz respeito às avaliaçóes que o público faz dos temas e atores políticos, a partir dos acontecimentos que são publicamente debatidos.

A partir da noção de priming, e considerando que os meios de comunicaçáo são uma das principais fontes de informação dos cidadãos, espera-se que a exposição à mídia possa variar a avaliação do governo, mas esta variação possui diversas matizes e são limitadas. Na medida em que a opinião pública pode ser afetada pela forma como a mídia elenca os temas a serem debatidos e direciona a interpretação das notícias, que pode ser positiva ou negativa. Ainda na esteira dos efeitos de priming, sugere-se que os cidadáos expostos à mídia pública (governamental) tendem a avaliar melhor $\mathrm{o}$ governo. Portanto, pode-se pensar que as informaçóes são transmitidas pela mídia de um certo modo (agendamento) e com uma determinada conformaçáo (enquadramento), e pode ativar esquemas mentais (priming).

No entanto, a existência de certa dependência cognitiva do público não significa que a mídia controle a mente dessa audiência, como defendido por algumas teorias da comunicação nas primeiras décadas do século XX, a exemplo da Teoria da Agulha Hipodérmica. Essa percepção aos poucos foi alterada e deu espaço à hipótese de que a informação é mediada pelos chamados líderes de opinião (two step flow). A mera exposição aos meios de comunicação não é suficiente para alterar a opinião do cidadão-receptor. As informaçóes são recebidas e decodificadas de maneiras distintas pelos receptores, de acordo com seus valores, ideologias, tradiçóes, escolaridade e renda. Ademais, tanto a informação quanto a opinião pública não são totalmente neutras, na medida em que supóe opçóes interessadas por ambas partes.

Deste modo, a relevância da mídia sobre a popularidade pode ser relativizada. Existem controvérsias interpretativas (PORTO, 2007) nas formulaçôes dos emissores e receptores e os diferentes níveis de negociação de significados, desde a adesão acrítica aos enquadramentos dominantes da mídia (seja em produtos noticiosos ou não) e chegam à negociação e à oposição. Não é apenas a "elite cognitiva" que organiza cotidianamente as interpretaçôes sobre política: outros atores sociais, 
inclusive o próprio governo, disputam os pontos de vista e a agenda, e isso depende tanto do tema quanto das forças envolvidas.

\section{Escolaridade, hábitos de mídia e avaliação de governo}

Em 2013, a avaliação do governo da presidente Dilma Rousseff variou bastante e, um dos fatores responsáveis por esta volatilidade, foram as Jornadas de Junho de 2013, que produziram uma queda abrupta de mais de 30 pontos percentuais na avaliação do seu governo. Em março de 2013 a avaliação positiva era de $63 \%$, em setembro desceu para $37 \%$ e voltou a subir novamente, alcançado $43 \%$ em dezembro (Ibope). Em setembro de 2013, a maior parte do contingente que aprovava o governo da presidente Dilma Rousseff era formado por eleitores com baixa escolaridade. Tal grupo, além de possuir maior predisposição a aprovar o governo da presidente se diferenciava quanto à preferência dada aos veículos de comunicação. A Tabela 1 demonstra como se dá a distribuição do apoio ao governo pela escolaridade dos cidadáos.

Tabela 1 - Aprovação do governo da presidente Dilma Rousseff pela escolaridade dos eleitores (\%)

\begin{tabular}{c|c|c|c}
\hline Escolaridade & Aprova & Nem aprova e nem reprova & Reprova \\
\hline Baixa & 20,4 & 13,4 & 10,3 \\
\hline Média & 67,2 & 72 & 72,2 \\
\hline Alta & 12,5 & 14,6 & 17,5 \\
\hline
\end{tabular}

Fonte: Pesquisa Brasileira de Mídia 2014 (BRASIL, 2013).

O público com menor escolaridade dá maior preferência à televisão (84\%) e, ao alcançar a escolaridade alta, cai o número de espectadores da TV (68,2\%). Para o público com maior escolaridade e, consequentemente, maior renda, a redução da importância da televisão diminui devido, sobretudo, ao acesso à internet $(23,6 \%)$ (Tabela 2). Isto é, o público mais escolarizado e com maior renda se diferenciará dos demais pelo baixo apoio ao governo da presidente e pelo desprestígio à mídia tradicional, sobretudo, a TV. Como veremos adiante, essa distinção na preferência desses dois grupos refletirá na identificação acerca de quais problemas do país são mais significativos. 
Tabela 2 - Principal veículo de comunicação por escolaridade (\%)

\begin{tabular}{c|c|c|c}
\hline \multirow{2}{*}{ Veículos de comunicaçáo } & \multicolumn{3}{|c}{ Escolaridade } \\
\cline { 2 - 4 } & Baixa & Média & Alta \\
\hline TV & 84,0 & 77,1 & 68,2 \\
\hline Rádio & 11,3 & 7,0 & 5,0 \\
\hline Jornal impresso & 0,8 & 1,5 & 2,1 \\
\hline Revista impressa & 0,1 & 0,3 & 0,4 \\
\hline Internet & 2,7 & 13,4 & 23,6 \\
\hline Conversa com amigos/ conhecidos/ \\
parentes & 0,3 & 0,3 & 0,3 \\
\hline Náo sabe & 0,4 & 0,1 & 0,2 \\
\hline Náo respondeu & 0,3 & 0,3 & 0,1 \\
\hline
\end{tabular}

Fonte: Pesquisa Brasileira de Mídia 2014 (BRASIL, 2013).

É claro que os hábitos iniciais de exposição às mídias podem ser herdados a partir de familiares, colegas e amigos, com os quais os cidadãos estabelecem relaçóes durante o processo de socializaçáo. Tais hábitos podem afetar o consumo de novas mídias posteriormente, quando o indivíduo estiver em processo de escolarização. Contudo, as pessoas são escolarizadas e depois consomem mídia e não se escolarizam mais porque consomem mais internet. Essa cisão provocada pela escolaridade e renda nos oferece o seguinte cenário: apoiadores do governo Dilma, que são aqueles que dão mais relevância à TV, e opositores ao governo Dilma, que são mais conectados à internet (Tabela 3). A partir daí, quando necessário, cada grupo utiliza o meio de comunicação de sua preferência para sustentar as suas predisposiçóes políticas. Isto é, em sua maioria, aqueles que aprovam o governo darão audiência a programas de TV neutros ou favoráveis à presidente, enquanto opositores buscarão sites imparciais ou contrários ao governo.

Além disso, é preciso considerar que o impacto dos veículos de comunicação será limitado pelo baixo interesse dos eleitores sobre o governo. Um dos fatores que reduz o interesse por notícias é o clima gerado pela alta popularidade do presidente e do seu governo (ABRAMSON, ARTERTON e ORREN, 1988; FIORINA, 1981). A alta popularidade cria a sensação de que está tudo indo bem, e, por esse motivo, reduz a necessidade dos eleitores constantemente se informar sobre as açóes do presidente.

Em todo caso, os eleitores que aprovam o governo Dilma Rousseff serão aqueles que demonstram maior interesse por notícias sobre o governo (Tabela 3). Isto é, em momentos de alta ou de baixa popularidade, aqueles que reprovam um governo 
estarão mais próximos do bloco que não dá atenção às notícias sobre o mesmo governo. Diante disso, é possível presumir que os apoiadores da presidente estão mais abertos à recepção de informaçôes produzidas pela propaganda governamental ou provenientes de notícias positivas sobre medidas da presidente.

$\mathrm{Na}$ maioria das vezes, as notícias só apresentam impacto significativo se os cidadãos confiam no emissor e entendem a necessidade de se manterem informados (JOHNSON e KAYE, 2000; KIOUSIS, 2001). No caso daqueles que reprovam o governo há baixa confiança e desinteresse nas mensagens transmitidas por representantes do governo.

Tabela 3 - Avaliação do governo Dilma Rousseff e interesse em notícias sobre o governo federal

\begin{tabular}{l|c|c|c}
\hline \multirow{2}{*}{} & \multicolumn{3}{|c}{ Avaliaçáo } \\
\cline { 2 - 4 } & Aprova & Nem aprova e nem reprova & Reprova \\
\hline Muito interesse & 41,0 & 41,1 & 17,8 \\
\hline Interesse médio & 35,0 & 47,5 & 17,4 \\
\hline Pouco interesse & 31,5 & 45,4 & 23,1 \\
\hline Nenhum interesse & 24,3 & 39,1 & 36,6 \\
\hline Náo sabe & 35,3 & 40,2 & 24,5 \\
\hline Náo respondeu & 33,5 & 43,1 & 23,4 \\
\hline
\end{tabular}

Fonte: Pesquisa Brasileira de Mídia 2014 (BRASIL, 2013).

O desinteresse dos eleitores surge como uma barreira à mudança de opiniáo sobre o governo. Com baixo interesse, boa parte da opiniáo pública permanece alheia aos noticiários, enquanto a parcela que dá atenção ao noticiário utiliza as informaçóes recebidas apenas para reforçar suas predisposiçôes. Esses fatores são agravados quando o foco dos problemas não está próximo da realidade dos sujeitos.

Além da desigualdade do efeito da mídia sobre eleitores como reflexo da renda e escolaridade, há ainda outra assimetria que decorre de barreiras criadas às sugestôes por fatores individuais como, por exemplo, identificação partidária ou experiência com governos anteriores que faz com que existam predisposiçóes dos eleitores sobre as informaçóes políticas. Tais predisposiçóes dificultam com que o noticiário afete todos os indivíduos da mesma forma e, além disso, promovem a prática da exposição seletiva.

Por mais complexa que seja a questão política, a maioria dos eleitores mantém constante aferiçôes sobre o mundo político. A análise que eles conduzem é de dois tipos: memory-based, quando o passado predomina sobre a interpretação do presente 
ou impressiondriven onde as novas informaçóes apresentam a capacidade de redefinir a compreensão acerca do ambiente político ${ }^{3}$ (LODGE e TABER, 2005).

No modelo memory-based, o julgamento sobre o presidente e, consequente sobre o seu governo, varia conforme o conjunto de experiências vividas e sugestóes. As experiências pessoais estabelecem modelos (esquemas) que funcionam como parâmetro para compreender o presente (LODGE, MCGRAW e STROH, 1989). Por sua vez, tais modelos são ativados por meio de sugestôes lançadas, sobretudo, pela família, amigos, meios de comunicação e especialistas (LODGE e TABER, 2000).

Porém, nem todas as sugestôes serão aceitas, pois os indivíduos possuem suas convicçóes e a elas se agarram e relutam em contradizê-las. Esse é um dos motivos que faz com que os efeitos da mídia não sejam percebidos nem ocorram em todos os eleitores. Para que ela tenha efeito é preciso que os indivíduos tenham interesse pela política, acesso, confiança nos veículos de comunicação e, sobretudo, não deixem suas preconcepçóes orientarem o consumo de notícias (EDWARDS e GALLUP, 1990).

As preconcepçóes conduzem o eleitor a ler as notícias da forma que lhe agrada. Isso se torna mais frequente em cenários de maior acirramento da concorrência entre os veículos de comunicação. Com o aumento da disputa pela audiência, os veículos de comunicação perdem a capacidade de indicar o que o público deve consumir e a audiência ganha a capacidade de determinar o que deve ser exibido.

Essa mudança na postura dos veículos de comunicação é reflexo das várias transformaçôes a que eles foram submetidos nos últimos anos. Tais transformaçôes decorreram, sobretudo, das alteraçóes na postura do público, dos avanços tecnológicos e de uma crise econômica estrutural. $\mathrm{O}$ público agora requer maior interação e notícias cada vez mais instantâneas (SUNSTEIN, 2009).

Os reflexos desse novo tempo são vistos, principalmente, nas readequaçóes que a televisão foi submetida e o seu esvaziamento como principal difusor de notícias. Por muito tempo, poucos canais de televisão centralizaram a atenção da opinião pública, entretanto, nos últimos anos, esse cenário já não é o mesmo. Isto porque as mudanças tecnológicas ampliaram as fontes de informação e, consequentemente, fortaleceram a capacidade de os indivíduos selecionarem as notícias que desejam receber.

O aumento das fontes de informação fragmenta o público, pois é maior a chance de os eleitores utilizarem a mídia como entretenimento e se distanciarem do

\footnotetext{
${ }^{3}$ Para Brody (1991), tanto as avaliaçóes memory based quanto as do tipo impression-driven variam conforme o noticiário sobre as açóes políticas do presidente.
} 
noticiário político (STROUD, 2008; PRIOR, 2005 e 2007) ou se especializarem em tópicos específicos, como, por exemplo, receber notícias somente sobre questóes ambientais (GALSTON, 2003; SUNSTEIN, 2001). A variedade de informação disponível favorece aos indivíduos limitarem sua atenção apenas para um pequeno conjunto de questóes. Assim, se tornam especialistas em uma determinada temática mantendo contato com os principais especialistas do assunto. Porém, serão completamente alheios a discussão sobre outros problemas nacionais.

No caso da avaliação do governo, os sujeitos costumam recorrer a veículos que confirmam suas preconcepçóes acerca do desempenho do presidente. Além disso, como dito anteriormente, o público que aprova o governo passa a ser aquele que dedica menos atenção aos veículos de comunicação, sobretudo, aos noticiários. De acordo com o Gráfico 1, a chance de encontrar sujeitos que não dedicam atenção aos veículos de comunicação será maior entre aqueles que aprovam o governo (ótimo/bom). A exceção dessa regra aparece apenas no tocante à TV.

Gráfico 1 - Audiência dos veículos de comunicação por aprovação do governo Federal

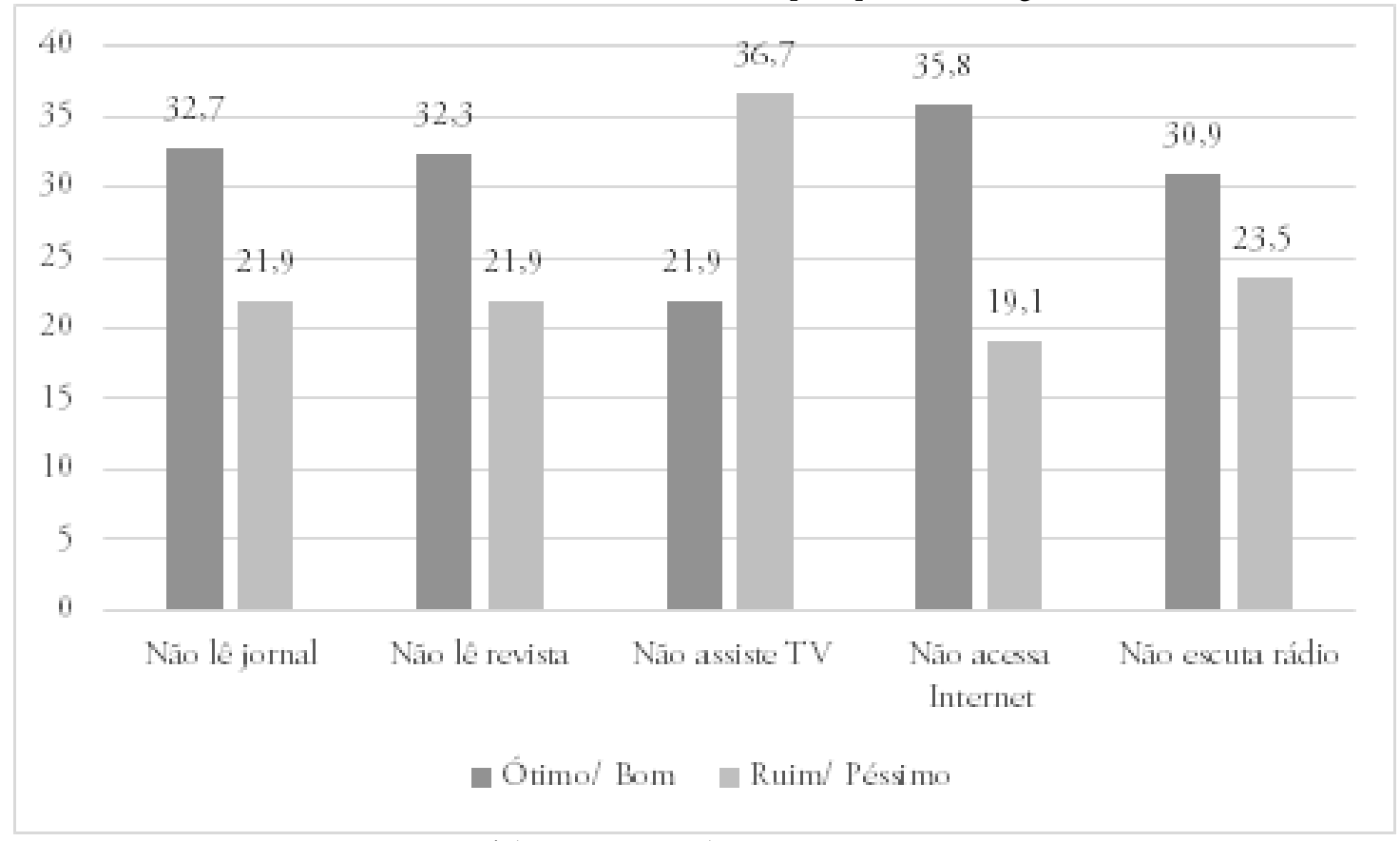

Fonte: Pesquisa Brasileira de Mídia 2014 (BRASIL, 2013). 
A aprovação do governo Dilma Rousseff, em setembro de 2013, mantém vínculo com a renda individual, isto é, sujeitos com baixa renda tendem a aprovar o governo, enquanto, aqueles com renda elevada o reprovam. Como dito anteriormente, o par renda e escolaridade afeta diretamente a forma como os sujeitos utilizarão os veículos de comunicaçáo. Aqueles com baixa renda e baixa escolaridade utilizarão com mais frequência a TV.

Devido a essa característica, boa parte dos que aprovam o governo de Dilma Rousseff são mais ligados à TV. O que não significa que a TV altere a percepção desses indivíduos sobre o desempenho do governo. Por sua vez, aqueles que reprovam o governo possuem acesso a veículos diversificados como jornais, revistas e sites da internet. Porém, como já dito, possuem baixo interesse pelas açôes do governo.

Com maior número de fontes de informação, os eleitores que reprovam o governo mantêm com maior facilidade a prática da exposição seletiva ${ }^{4}$. $\mathrm{O}$ acesso a um conjunto maior de veículos de informação possibilita aos indivíduos consumirem apenas notícias que satisfaçam as suas preconcepçôes (KINDER, 2003). As notícias que causam desconforto são, geralmente, substituídas por outras mais favoráveis. Isso é visto, sobretudo, entre usuários da internet e TV por assinatura, pois elas permitem aos espectadores definirem a quais tipos de informaçóes serão submetidos.

A utilização de exposição seletiva varia conforme a disponibilidade de fontes de informação e ao peso que as preconcepções possuem sobre a vida do indivíduo. $\mathrm{Na}$ maioria das vezes, as informaçóes acolhidas são aquelas que permitem a manutenção do comportamento já existente ou legitimam tendências individuais.

A prática da exposição seletiva favorece o aumento do distanciamento entre os sujeitos que apresentam maior interesse pela política daqueles com baixo interesse. Enquanto o público que demonstra maior interesse busca notícias sobre a política e a economia, o segundo grupo irá atrás de entretenimento (PRIOR, 2005). Isso faz com que o público que procura informaçóes políticas tenha mais conhecimento sobre as questôes nacionais e sobre como o governo age, já aqueles que desejam entretenimento terão baixo conhecimento político e atribuirão baixa relevância ao presidente. $\mathrm{Na}$ próxima seção veremos quais fatores impactam na percepção sobre os problemas nacionais.

\footnotetext{
${ }^{4}$ Por outro lado, é preciso ressaltar que a maior quantidade de canais de comunicaçáo ampliou o espaço concedido para que o presidente possa dialogar com o público. Os avanços na tecnologia diminuíram a distância entre os eleitores e os governantes, ampliaram a fiscalização sobre as açóes do governo e impulsionaram a mobilização de militantes.
} 


\section{Avaliação do governo e percepção dos problemas nacionais}

O suporte público é reflexo da análise dos eleitores sobre as medidas desenvolvidas pelo governo. Eleitores satisfeitos aprovam o presidente e dáo a ele o seu apoio, enquanto eleitores insatisfeitos migram para a oposiçáo ao governo. Porém, os critérios que os cidadãos utilizam para julgar o governo não são rígidos e se alteram a partir de estímulos lançados pelo governo, pela oposição, pela mídia e mesmo pela conjuntura econômica.

Durante todo o mandato, o governante e os seus opositores travam disputa para controlar a forma como a opiniáo pública julga o desempenho do governo (SAMPAIO, 2014). Essa disputa passa pela imputação de responsabilidade ao presidente e pelo destaque dado a determinados temas em detrimento de outros. Para a oposição, é estratégico que açôes negativas do presidente permaneçam em evidência, já que o governo buscará ampliar o eco de suas medidas consideradas positivas.

Nesse cenário, os veículos de comunicação surgem como meios onde as táticas do governo e da oposição, para direcionar a opiniáo pública, são efetivadas. Como vimos anteriormente, a hipótese do agenda-setting sustenta que o efeito da mídia decorre, sobretudo, da capacidade de fazer com que um conjunto de questóes ganhe notoriedade e passem a orientar o comportamento dos cidadãos. Assim, a mídia exerceria a função de direcionar a atenção dos cidadãos para questóes específicas e induzir a crença de que elas são relevantes. Além disso, ocuparia o papel de indicar sobre quais critérios tais questóes devem ser analisadas e qual a responsabilidade do presidente sobre elas (efeito prime).

Essa tentativa de interferência da mídia é limitada. Quando ela ocorre, é sobretudo, no redimensionamento das grandes questôes nacionais, pois "esses problemas que recebem destaque no noticiário nacional tornam-se na visão do público os mais importantes da naçáo" (IYENGAR e KINDER, 2010, p. 16). Acredita-se que a partir dos estímulos midiáticos, os sujeitos passariam a debater acerca dos problemas nacionais (MUNDIM, 2010). Dessa forma, quanto maior a cobertura sobre determinado evento maior seria a possibilidade de ele ser visto como relevante e, a partir disso, impactar o suporte público do presidente. É a atribuição de relevância que faz com que as questóes tenham consequências políticas, isto é, incidam sobre a postura do governo ou alterem o seu suporte público.

O enquadramento dado pela mídia torna mais fácil para o eleitor identificar quais problemas são nacionais e quais são individuais. Esse último diz respeito aqueles problemas cuja origem ou solução dependem do eleitor e não do governo. Já os nacionais têm raiz nas açóes desenvolvidas pelo presidente. Entre os principais problemas nacionais apontados pelos eleitores se destacavam em 2013: corrupção, 
educação, saúde, impostos, juros, salários e custo de vida . Porém, é preciso ressaltar que tais problemas se sobressaem, principalmente, por não se distanciarem do cotidiano do eleitor. No momento em que os efeitos náo forem percebidos diretamente no bem-estar individual, eles deixarão de ser tratados como prioritários.

Nesse ponto, a teoria do agenda-setting falha ao subestimar a relevância das experiências individuais para a compreensão dos fatos políticos. No processo informacional acerca dos problemas individuais, as experiências pessoais estáo em patamar superior ao da mídia. Por esse motivo, muitas vezes, notícias relacionadas à economia não apresentam qualquer efeito político visível, já que as experiências individuais indicam como e quais informaçóes devem ser absorvidas. Por exemplo, o eleitor que está em dificuldades financeiras dificilmente mudará sua visão sobre a economia pela simples exposição ao noticiário. Isso explica por que apesar da cobertura da mídia ser negativa em relação ao presidente Lula, ele conseguiu se reeleger em 2006: a cobertura negativa não encontrava eco entre os cidadãos mais pobres, que eram beneficiados pelas políticas públicas (MUNDIM, 2014).

Essas mesmas experiências individuais serão significativas para a compreensão do contexto nacional. A leitura dos problemas nacionais é feita a partir do ponto de vista individual. Por esse motivo é que alguns grupos veem um conjunto de questóes como relevantes e outros não dão tanta importância ao mesmo tema. Esse vem a ser o caso da corrupção, por exemplo, eleitores com ensino fundamental incompleto apresentam mais chances de não a perceberem como principal problema nacional (Tabela 4). É possível supor que eles possuem outras questóes mais urgentes no seu cotidiano e creem que deveriam ser tratadas como tal pela agenda da mídia e do governo.

Outro fator, que reduz a capacidade de a mídia enquadrar os problemas ou gerar efeitos primes, é a aliança existente entre preconcepçóes sobre o governo e a atenção às questóes políticas. Como dito anteriormente, o grau de apreço ao governo direciona a atenção dos cidadãos sobre as questóes políticas e indica quais veículos merecem confiança. Por exemplo, "há uma tendência dos eleitores pró governo verem a economia sob uma luz mais rosada do que os eleitores da oposiçáo" (NANNESTAD e PALDAM, 1994, p. 232). No caso de questóes como corrupção, educação, saúde, impostos, juros, salários e custo de vida, essa distinção também se mantém (Tabela 4). Isto porque os eleitores que aprovam o governo são mais contumazes em não admitir a existência de qualquer tipo de problema nacional.

\footnotetext{
${ }^{5}$ Fonte: Pesquisa Brasileira de Mídia 2014 (BRASIL, 2013).
} 
A seguir será apresentado um modelo multinominal de percepção acerca do principal problema nacional no país em 2013. A percepção dos problemas nacionais é nossa variável dependente e, neste caso, a avaliação de governo passa a ser uma variável independente. Além disso, introduzimos, no modelo, variáveis sociológicas como escolaridade e regiáo do país -, além das midiáticas: frequência, em horas, com que assiste TV, ouve rádio e acessa a internet, principal meio de comunicação e principal programa de TV - Jornal Nacional ou Jornal da Record, que foram os mais citados pelos informantes.

Tabela 4 - Modelo multinomial de percepção acerca do principal problema nacional

\begin{tabular}{|c|c|c|c|c|c|c|c|c|c|}
\hline & & \multicolumn{2}{|c|}{ Corrupção } & \multicolumn{2}{|c|}{ Educaçáo } & \multicolumn{2}{|c|}{$\begin{array}{l}\text { Impostos, juros, } \\
\text { salários e custo de }\end{array}$} & \multicolumn{2}{|c|}{ Saúde } \\
\hline & & B & $\operatorname{Exp}(B)$ & B & $\operatorname{Exp}(B)$ & B & $\operatorname{Exp}(B)$ & B & $\operatorname{Exp}(B)$ \\
\hline & Intercepto & $-1,297$ & & $\begin{array}{c}- \\
1,164^{* * *} \\
\end{array}$ & & $\begin{array}{c}- \\
2,100^{* * *}\end{array}$ & & $\begin{array}{c}- \\
0,932^{* * *}\end{array}$ & \\
\hline \multirow[t]{2}{*}{ Avaliação } & Ótimo/ Bom & $\begin{array}{c}-0,172^{* * *} \\
(0,063)\end{array}$ & 0,842 & $0,193^{* * *}$ & 0,824 & $\begin{array}{l}-0,121^{*} \\
(0,069)\end{array}$ & 0,886 & $0,142^{* * *}$ & 0,868 \\
\hline & Ruim/ Péssimo & $\begin{array}{l}0,165^{* *} \\
(0,067) \\
\end{array}$ & 1,180 & $\begin{array}{c}0,027 \\
(0,067) \\
\end{array}$ & 1,027 & $\begin{array}{c}0,078 \\
(0,076) \\
\end{array}$ & 1,081 & $\begin{array}{l}0,101^{* *} \\
(0,046) \\
\end{array}$ & 1,107 \\
\hline \multirow[t]{2}{*}{ Escolaridade } & $\begin{array}{l}\text { Ensino Fund. } \\
\text { incompleto }\end{array}$ & $\begin{array}{c}-0,321^{* * *} \\
(0,074)\end{array}$ & 0,726 & $\begin{array}{c}- \\
0,463^{* * *}\end{array}$ & 0,629 & $\begin{array}{l}-0,101 \\
(0,081)\end{array}$ & 0,904 & $\begin{array}{l}-0,074 \\
(0,048) \\
\end{array}$ & 0,928 \\
\hline & $\begin{array}{l}\text { Ensino Fund } \\
\text { comp/ Ens. }\end{array}$ & $\begin{array}{l}-0,135^{*} \\
(0,070)\end{array}$ & 0,874 & $\begin{array}{c}- \\
0,230^{* * *}\end{array}$ & 0,795 & $\begin{array}{l}-0,082 \\
(0,080)\end{array}$ & 0,921 & $\begin{array}{c}- \\
0,209^{* * *}\end{array}$ & 0,811 \\
\hline \multirow[t]{2}{*}{ Regiāo } & $\begin{array}{l}\text { Norte/ } \\
\text { Nordeste }\end{array}$ & $\begin{array}{c}-0,937^{* * *} \\
(0,093)\end{array}$ & 0,392 & $\begin{array}{l}-0,158 \\
(0,107) \\
\end{array}$ & 0,853 & $\begin{array}{c}-0,283^{* *} \\
(0,131) \\
\end{array}$ & 0,753 & $\begin{array}{l}0,129^{*} \\
(0,077)\end{array}$ & 1,138 \\
\hline & Sul/ Sudeste & $\begin{array}{c}-0,519^{* * *} \\
(0,085) \\
\end{array}$ & 0,595 & $\begin{array}{c}0,119 \\
(0,102)\end{array}$ & 1,126 & $\begin{array}{c}0,467^{\text {*** }} \\
(0,123)\end{array}$ & 1,595 & $\begin{array}{c}0,441^{\text {*** }} \\
(0,074)\end{array}$ & 1,554 \\
\hline \multirow[t]{3}{*}{ Horas (TV) } & Náo assiste TV & $\begin{array}{l}-0,190 \\
(0,180) \\
\end{array}$ & 0,827 & $\begin{array}{l}-0,024 \\
(0,198) \\
\end{array}$ & 0,976 & $\begin{array}{c}- \\
0,604^{* * *} \\
\end{array}$ & 0,547 & $\begin{array}{l}-0,218^{*} \\
(0,135) \\
\end{array}$ & 0,804 \\
\hline & Até 2 horas & $\begin{array}{c}-0,309^{* *} \\
(0,158)\end{array}$ & 0,734 & $\begin{array}{c}0,000 \\
(0,175) \\
\end{array}$ & 1,000 & $\begin{array}{l}-0,208 \\
(0,178 \\
\end{array}$ & 0,812 & $\begin{array}{l}-0,006 \\
(0,118) \\
\end{array}$ & 0,994 \\
\hline & $\begin{array}{l}\text { Mais de } 2 \text { até } \\
10 \text { hs }\end{array}$ & $\begin{array}{l}-0,249 \\
(0,156) \\
\end{array}$ & 0,779 & $\begin{array}{c}0,099 \\
(0,173)\end{array}$ & 1,104 & $\begin{array}{l}-0,197 \\
(0,176)\end{array}$ & 0,821 & $\begin{array}{c}0,024 \\
(0,116) \\
\end{array}$ & 1,025 \\
\hline \multirow[t]{3}{*}{$\begin{array}{l}\text { Horas } \\
\text { (Rádio) }\end{array}$} & $\begin{array}{l}\text { Náo escuta } \\
\text { rádio }\end{array}$ & $\begin{array}{c}0,084 \\
(0,208)\end{array}$ & 1,087 & $\begin{array}{l}0,414^{*} \\
(0,238)\end{array}$ & 1,514 & $\begin{array}{l}-0,091 \\
(0,216)\end{array}$ & 0,913 & $\begin{array}{l}-0,135 \\
(0,134)\end{array}$ & 0,873 \\
\hline & Até 6 horas & $\begin{array}{c}0,052 \\
(0,207)\end{array}$ & 1,054 & $\begin{array}{l}0,405^{*} \\
(0,237)\end{array}$ & 1,499 & $\begin{array}{l}-0,015 \\
(0,214)\end{array}$ & 0,985 & $\begin{array}{l}-0,073 \\
(0,132)\end{array}$ & 0,929 \\
\hline & $\begin{array}{l}\text { Mais de } 6 \text { até } \\
10 \text { hs }\end{array}$ & $\begin{array}{l}-0,176 \\
(0,245)\end{array}$ & 0,839 & $\begin{array}{c}0,360 \\
(0,265)\end{array}$ & 1,433 & $\begin{array}{c}0,020 \\
(0,246)\end{array}$ & 1,021 & $\begin{array}{l}-0,096 \\
(0,154)\end{array}$ & 0,908 \\
\hline \multirow[t]{3}{*}{ Dias (Jornal) } & Náo lê jornal & $\begin{array}{c}-0,227^{* *} \\
(0,110)\end{array}$ & 0,797 & $\begin{array}{c}-0,246^{* *} \\
(0,106)\end{array}$ & 0,782 & $\begin{array}{c}0,013 \\
(0,129)\end{array}$ & 1,013 & $\begin{array}{l}0,156^{* *} \\
(0,083)\end{array}$ & 1,169 \\
\hline & Até 2 dias & $\begin{array}{c}-0,264^{* *} \\
(0,127)\end{array}$ & 0,768 & $\begin{array}{c}-0,299^{* *} \\
(0,122)\end{array}$ & 0,741 & $\begin{array}{c}-0,336^{* *} \\
(0,153)\end{array}$ & 0,715 & $\begin{array}{c}0,034 \\
(0,093)\end{array}$ & 1,035 \\
\hline & $\begin{array}{l}\text { Entre } 3 \text { e } 6 \\
\text { dias }\end{array}$ & $\begin{array}{c}0,117 \\
(0,134) \\
\end{array}$ & 1,124 & $\begin{array}{l}-0,105 \\
(0,132) \\
\end{array}$ & 0,900 & $\begin{array}{l}-0,236 \\
(0,170) \\
\end{array}$ & 0,790 & $\begin{array}{l}-0,039 \\
(0,105) \\
\end{array}$ & 0,962 \\
\hline \multirow[t]{2}{*}{$\begin{array}{l}\text { Dias } \\
\text { (revista) }\end{array}$} & Nenhum & $\begin{array}{l}0,695^{* *} \\
(0,312)\end{array}$ & 2,004 & $\begin{array}{l}-0,074 \\
(0,221) \\
\end{array}$ & 0,928 & $\begin{array}{c}0,536 \\
(0,345)\end{array}$ & 1,709 & $\begin{array}{c}0,101 \\
(0,171)\end{array}$ & 1,106 \\
\hline & $\begin{array}{l}\text { Entre } 1 \text { e } 2 \\
\text { dias }\end{array}$ & $\begin{array}{c}0,870^{* * *} \\
(0,319) \\
\end{array}$ & 2,387 & $\begin{array}{c}0,029 \\
(0,230) \\
\end{array}$ & 1,029 & $\begin{array}{c}0,606 \\
(0,356)^{*}\end{array}$ & 1,833 & $\begin{array}{c}0,126 \\
(0,179)\end{array}$ & 1,135 \\
\hline
\end{tabular}


Os limites da agenda-setting na popularidade do presidente | $\mathbf{1 3 5}$

\begin{tabular}{|c|c|c|c|c|c|c|c|c|c|}
\hline & $\begin{array}{l}\text { Entre } 3 \text { e } 6 \\
\text { dias }\end{array}$ & $\begin{array}{c}0,501 \\
(0,353) \\
\end{array}$ & 1,651 & $\begin{array}{l}-0,025 \\
(0,262) \\
\end{array}$ & 0,976 & $\begin{array}{c}0,683 \\
(0,387)^{*} \\
\end{array}$ & 1,980 & $\begin{array}{l}-0,019 \\
(0,205) \\
\end{array}$ & 0,981 \\
\hline \multirow[t]{3}{*}{$\begin{array}{l}\text { Horas } \\
\text { (internet) }\end{array}$} & Náo acessa & $\begin{array}{c}0,081 \\
(0,121)\end{array}$ & 1,085 & $\begin{array}{c}- \\
0,472^{* * *}\end{array}$ & 0,624 & $\begin{array}{c}0,144 \\
(0,142)\end{array}$ & 1,154 & $\begin{array}{c}0,229^{* * *} \\
(0,088)\end{array}$ & 1,257 \\
\hline & Até 2 horas & $\begin{array}{c}0,005 \\
(0,123) \\
\end{array}$ & 1,005 & $\begin{array}{c}-0,257^{* *} \\
(0,107)\end{array}$ & 0,774 & $\begin{array}{c}0,071 \\
(0,144) \\
\end{array}$ & 1,074 & $\begin{array}{c}0,295^{\text {*** }} \\
(0,088)\end{array}$ & 1,344 \\
\hline & $\begin{array}{l}\text { Mais de } 2 \text { até } \\
6 \mathrm{hs}\end{array}$ & $\begin{array}{c}0,188 \\
(0,121)\end{array}$ & 1,207 & $\begin{array}{l}-0,101 \\
(0,106)\end{array}$ & 0,904 & $\begin{array}{c}0,057 \\
(0,146)\end{array}$ & 1,059 & $\begin{array}{c}0,124 \\
(0,090)\end{array}$ & 1,132 \\
\hline \multirow{4}{*}{$\begin{array}{l}\text { Principal } \\
\text { meio de } \\
\text { comunicação }\end{array}$} & TV & $\begin{array}{c}0,173 \\
(0119) \\
\end{array}$ & 1,188 & $\begin{array}{c}0,127 \\
(0,119) \\
\end{array}$ & 1,136 & $\begin{array}{l}-0,101 \\
(0,116) \\
\end{array}$ & 0,904 & $\begin{array}{c}0,089 \\
(0,073) \\
\end{array}$ & 1,093 \\
\hline & Internet & $\begin{array}{l}0,329^{* *} \\
(0,139)\end{array}$ & 1,390 & $\begin{array}{l}0,283^{* *} \\
(0,135)\end{array}$ & 1,326 & $\begin{array}{l}-0,016 \\
(0,147) \\
\end{array}$ & 0,984 & $\begin{array}{l}0,156^{*} \\
(0,091) \\
\end{array}$ & 1,169 \\
\hline & $\begin{array}{l}\text { Jornal } \\
\text { impresso }\end{array}$ & $\begin{array}{l}0,346^{*} \\
(0,198)\end{array}$ & 1,413 & $\begin{array}{c}0,074 \\
(0,207)\end{array}$ & 1,076 & $\begin{array}{l}-0,331 \\
(0,253)\end{array}$ & 0,718 & $\begin{array}{l}-0,072 \\
(0,149) \\
\end{array}$ & 0,931 \\
\hline & Revista & $\begin{array}{c}0,006 \\
(0,433)\end{array}$ & 1,006 & $\begin{array}{c}0,448 \\
(0,343)\end{array}$ & 1,565 & $\begin{array}{l}-0,462 \\
(0,539)\end{array}$ & 0,630 & $\begin{array}{l}-0,014 \\
(0,296)\end{array}$ & 0,986 \\
\hline \multirow{2}{*}{$\begin{array}{l}\text { Principal } \\
\text { programa de } \\
\text { TV }\end{array}$} & $\begin{array}{l}\text { Jornal } \\
\text { Nacional }\end{array}$ & $\begin{array}{c}0,274^{* * *} \\
(0,073)\end{array}$ & 1,315 & $\begin{array}{c}0,111 \\
(0,076)\end{array}$ & 1,117 & $\begin{array}{l}0,142^{*} \\
(0,084)\end{array}$ & 1,152 & $\begin{array}{c}0,253^{* * *} \\
(0,050)\end{array}$ & 1,288 \\
\hline & $\begin{array}{l}\text { Jornal da } \\
\text { Record }\end{array}$ & $\begin{array}{l}-0,216^{*} \\
(0,112)\end{array}$ & 0,806 & $\begin{array}{c}0,128 \\
(0,095)\end{array}$ & 1,137 & $\begin{array}{l}-0,073 \\
(0,116)\end{array}$ & 0,930 & $\begin{array}{l}-0,028 \\
(0,067)\end{array}$ & 0,972 \\
\hline
\end{tabular}

${ }^{* * *} \mathrm{p}<0,01{ }^{* *} \mathrm{p}<0,05{ }^{*} \mathrm{p}<0,10$

N: 18312. Chi2: 881,4 (sig. <0,00). Pseudo R2 de McFadden = 0,170

Var. Dependente: Qual o principal problema do país?

Categoria de referência: "Regular/ Outros"; "Ens. Superior completo"; "Centro-oeste"; "Mais de 10 horas"; "Mais de 10 horas"; "Todos os dias"; "Todos os dias"; "Mais de 6 horas"; "Rádio"; Outros.

Fonte: Pesquisa Brasileira de Mídia 2014 (BRASIL, 2013).

Assim, é preciso considerar que parte dos indivíduos analisa os problemas nacionais a partir da sua perspectiva individual. Em alguns casos, esses sujeitos encaram as questóes nacionais como se fossem pessoais. Com isso, tomam a experiência individual como principal fonte de informação. Isso faz com que a percepção deles sobre as questóes políticas seja imune à exposição ao noticiário (MUTZ, 1992). Os cidadáos entendem que sabem mais sobre suas vidas do que terceiros.

Os veículos de comunicação assumirão o protagonismo na identificação do que é relevante e no diagnóstico sobre como os problemas nacionais devem ser analisados apenas no momento em que a experiência individual não emita respostas para esse fim. Como a experiência dos sujeitos é preponderante à leitura dos problemas individuais, a capacidade de a mídia orientar a opiniáo pública será mais perceptível, sobretudo, no tocante às questóes nacionais.

Como vimos anteriormente, o acesso aos veículos de comunicação sofre interferência de fatores como a renda e a escolaridade, que criam clivagens quanto ao uso desses meios. A renda e a escolaridade serão preponderantes para a construção de experiências individuais e definição de perspectivas. Isso fará com que tenhamos 
sujeitos aproximados pelas experiências pessoais reunidos na audiência de determinados veículos, sobretudo, TV e internet.

Como dito anteriormente, os sujeitos que reprovam o governo Dilma Rousseff são encontrados em maior quantidade na internet. A internet possibilita a eles consumirem apenas as notícias que lhe interessam. Nesse sentido, enquanto os indivíduos que aprovam o governo são direcionados a refletir sobre temas agendados pela TV, esses atores são mais livres para acessar notícias mais próximas do cotidiano deles. Com isso, eles obtêm maior capacidade de vincular a atuação do governante a tópicos relevantes ao seu dia-a-dia.

$\mathrm{O}$ acesso à internet afeta a percepçáo de que a educação e a corrupçáo são os principais problemas do país. Aqueles que a têm como principal meio para obter notícias ampliam em 1,39 vezes a percepçáo da corrupção como maior mazela nacional (Tabela 4). Esse efeito só não é maior do que o registrado pelos jornais impressos sobre a sua audiência.

Apesar de a internet apresentar maior capacidade de municiar os sujeitos sobre questôes específicas, ela não tem força para suplantar as predisposiçóes individuais. Nesse meio, sujeitos que aprovam o governo encontrarão com facilidade notícias positivas sobre a presidente. Por sua vez, aqueles que a reprovam identificarão motivos que justificam tal posição.

Já a TV aberta apresenta baixa influência na identificaçáo de problemas nacionais por ser ponto de encontro daqueles que aprovam o governo Dilma Rousseff e por, em muitos casos, cumprir apenas função recreativa. Os eleitores que aprovam o governo da presidente não identificam problemas ou, quando fazem isso, não os relacionam com a atuação da presidente.

\section{Considerações finais: a relevância da escolaridade na avaliação do governo}

Nos últimos anos, os veículos de comunicação pelo mundo sofreram diversas transformaçóes. A principal delas está relacionada ao fortalecimento da internet, o que promoveu novas formas de interaçáo com o público. Esse crescimento do número de usuários da internet tem redimensionado o espaço ocupado por veículos tradicionais como TV, rádio e jornal. No Brasil, esse reposicionamento dos veículos de comunicação e, sobretudo, o esvaziamento da TV está ainda em estágio inicial. Isso se deve ao fato do acesso à internet se restringir a pouco mais de $40 \%$ dos brasileiros $^{6}$. Vale lembrar que esse número varia conforme a região: enquanto no

\footnotetext{
${ }^{6}$ Fonte: Sistema de Indicadores de Percepção Social (SIPS) - IPEA (BRASIL, 2014).
} 
Nordeste apenas 20,7\% conta com acesso à internet, no Sudeste esse número ultrapassa $50 \%$. O principal fator que dificulta a ampliação do número de usuários da internet é a renda, pois $59,6 \%$ dos brasileiros apontaram a falta de computador pessoal como principal motivo que impede o acesso à rede mundial de computadores. E, $14,1 \%$ dos brasileiros disseram não ter como pagar pela utilização da rede. Os excluídos por não saberem utilizar a internet representaram apenas $4,3 \%$ dos entrevistados, em pesquisa realizada em $2014^{7}$.

Esses fatores são cruciais para determinar os níveis desiguais de impacto da mídia sobre o público brasileiro. Isto é, a renda e a escolaridade condicionam a forma como os meios de comunicaçáo serão utilizados, posteriormente, denotam clara cisão na percepção sobre a imagem do governo. Dessa forma, a escolaridade e a renda são fundamentais para direcionar a interpretação dos eleitores sobre as açóes do governo, como, também, para determinar o modo como o público passará a utilizar os veículos de comunicação. A mídia possui efeitos limitados, uma vez que o acesso a ela e a escolha dos veículos e relevância das notícias dependeu em 2013 da escolaridade e da renda. Importa ressaltar, como já demonstrado por Mundim (2014), que os eleitores de menor nível de educação, e mais pobres, também foram os menos afetados em sua decisão de voto, pela cobertura negativa realizada pela mídia em relação ao então candidato Lula da Silva, o que contribuiu para a sua reeleição em 2006, a despeito da agenda da corrupçáo ser relevante naquele momento.

Por sua vez, como o apoio ao governo da presidente Dilma Rousseff, assim como ocorria nos governos de Lula da Silva, é maior entre os mais pobres justamente o público que dá maior audiência à televisão -, cria-se a falsa impressão da relação entre a popularidade presidencial e os veículos de comunicação. Na verdade, há relação espúria entre o tipo de veículo de comunicação utilizado e o suporte dado à presidente.

No geral, a avaliação sobre o desempenho do governante sofre muito mais o impacto de assuntos que afetam diretamente o cotidiano dos eleitores do que daqueles distantes de suas realidades. Por esse motivo, as questóes nacionais, sobretudo aquelas não vinculadas à economia, pouco interferem na imagem que os indivíduos formam acerca do presidente. Mudanças na forma como os sujeitos julgam o governo passam primeiro por alteraçôes na percepção sobre como o governo afeta o bem-estar individual.

Essa percepção varia conforme as expectativas e experiências vivenciadas pelos eleitores. Diante disso, a tarefa de enquadrar as questôes e apresentá-las como

\footnotetext{
${ }^{7}$ Fonte: Sistema de Indicadores de Percepção Social (SIPS) - IPEA (BRASIL, 2014).
} 
relevantes para os indivíduos é pouco eficiente. Os eleitores, por perceberem a melhora na sua qualidade de vida ou na daqueles mais próximos, não alteram o julgamento sobre o governo com base apenas em estímulos de terceiros como, por exemplo, a mídia.

No período aqui analisado, a avaliaçáo da presidente Dilma Rousseff tinha como base perceptível a clivagem provocada pelo par renda/escolaridade. Isto é, aprovaçáo marcadamente sustentada, em sua maioria, por eleitores com baixa escolaridade e baixa renda que se opunham à reprovação, em grande medida, alimentada por sujeitos com alta escolaridade e renda elevada. O principal motivo dessa cisão está na percepçáo sobre como as açóes do governo impactam no bem-estar individual. A partir desse ponto, os sujeitos dão mais atenção para fatos que corroboram com suas preconcepçóes sobre o governo.

Além disso, como a renda e a escolaridade limitam o acesso e influenciam diretamente a preferência dos indivíduos a determinados meios de comunicação, se torna fácil identificar a reuniáo de opositores e apoiadores em veículos específicos. Como boa parte daqueles que apoiam o governo Dilma Rousseff apresentam baixa escolaridade e baixa renda, eles serão encontrados com mais frequência em torno da televisão. Já os opositores estão mais presentes na internet, sobretudo, na audiência de sites que compartilham da visão que eles possuem sobre o governo.

A distribuição desigual do público entre os veículos reflete na agenda da mídia, pois, como todo produto, as notícias também são pensadas para agradar os seus consumidores. Dessa forma, a popularidade governamental também orienta o comportamento da mídia. Para os veículos tradicionais, cuja TV é um dos principais expoentes, não é estratégico criticar governos com suporte público elevado ou se omitir quando o mesmo enfrenta turbulências.

É preciso destacar que não será apenas a exposição ao veículo de comunicação que irá alterar a percepção do eleitor sobre o governo. Há o risco dos sujeitos, ao compararem os fatos narrados pela mídia com a realidade que vivem, descartarem essas informaçóes caso elas destoem da sua percepção individual. Além disso, nos veículos de comunicação, são as questóes nacionais que prevalecem. Entretanto, em muitos casos, os assuntos nacionais, por apresentarem pouco impacto perceptível no cotidiano individual, esbarram na indiferença da maioria do público. O público é heterogêneo e, se a mídia afeta a sua opinião sobre o governo, este efeito é segmentado por grupos e classes sociais (MUNDIM, 2014; TELLES, 2015), ou seja, o efeito da agenda-setting também é heterogêneo. Esse quadro só não será tão drástico na internet, pois nela a audiência tem maior facilidade para direcionar o conteúdo. $\mathrm{Na}$ internet cada indivíduo tem a possibilidade de acessar aquilo que considera como 
mais significativo. Com isso, as questôes mais visualizadas e debatidas serão aquelas com mais impacto para o cotidiano dos indivíduos.

Por outro lado, o público limitado à televisão convive com pouco espaço dedicado a assuntos que apresentem impacto para suas vidas. Esse fator faz com que alguns substituam o caráter informativo da TV por outros métodos, reservando a ela apenas função recreativa. Por exemplo, em vez da TV, eleitores egotrópicos poderão utilizar suas relações pessoais e a experiência individual para compreender as ações desenvolvidas pela presidente. É nesse cenário que aqueles com mais baixa renda e escolaridade se mantêm inertes a estímulos que contradizem a compreensáo deles sobre aquilo que de fato importa para suas vidas.

Deve se considerar que os dados de uma única fonte de análises - a Pesquisa Brasileira de Mídia -, não nos permite chegar de maneira direta e inequívoca às correlaçóes propostas entre renda, escolaridade e popularidade, pois os testes devem ser repetidos em outros contextos. Contudo, a pesquisa nos fornece subsídios para relativizarmos o papel dos meios de comunicação na avaliação dos governos e contribui para a necessária crítica às conclusôes muito rápidas que são extraídas a partir da hipótese exclusiva do agendamento, teoria que falha ao desconsiderar as predisposiçôes dos indivíduos, bem como o contexto nos quais as informaçôes são emitidas pelos meios de comunicação e processadas pela heterogênea opiniáo do público.

Helcimara Telles é Professora do Departamento de Ciência Política da Universidade Federal de Minas Gerais (UFMG) e Coordenadora do Grupo de Pesquisa "Opinião Pública, Marketing Político e Comportamento Eleitoral". É Doutora em Ciência Política pela Universidade de São Paulo. E-mail: mara-telles@uol.com.br.

- Thiago Sampaio é Professor do Curso de Ciência Política da Universidade Federal do Pampa (UNIPAMPA) e Coordenador do Programa de Pós-Graduação em Políticas Públicas da UNIPAMPA e Pesquisador do Grupo de Pesquisa "Opinião Pública, Marketing Político e Comportamento Eleitoral”. É Doutor em Ciência Politica pela UFMG. E-mail: thiagosampaio@unipampa.edu.br.

Érica Baptista é Doutoranda em Ciência Política pela UFMG e Pesquisadora do Grupo de Pesquisa "Opinião Pública, Marketing Político e Comportamento Eleitoral”. E-mail: anitaerica@gmail.com. 


\section{Referências}

ABRAMSON, Jefrey B.; ARTERTON, F. Christopher; ORREN, Gary R. The electronic commonwealth: the impact of new media technologies on democratic politics. New York: Basic Books, 1988.

ALDÉ, Alessandra. A construção da política. Rio de Janeiro: Editora FGV, 2004.

BERGER, Peter; LUCKMANN, Thomas. A construção social da realidade. Petrópolis: Vozes, 2003.

BRASIL. Presidência da República. Secretaria de Comunicação Social. Pesquisa Brasília de Mídia 2014: hábitos de consumo de mídia pela população brasileira. Brasília: Secom, 2013.

BRASIL. IPEA. Sistema de Indicadores de Percepção Social (SIPS) 2014 - IPEA. Disponível em: <http://www.secom.gov.br>. Acesso em: 15 out. 2014.

BRODY, Richard A. Assessing the president: the media, elite opinion, and public support. Stanford: Stanford University Press, 1991.

CHAMPAGNE, Patrick. Formar a opinião: o novo jogo político. Petrópolis: Editora Vozes, 1998.

CHARAUDEAU, Patrick. Uma análise semiolinguística do texto e do discurso. In: PAULIUKONIS, Maria Aparecida; GAVAZZI, Sigrid (Orgs.). Da língua ao discurso: reflexóes para o ensino. Rio de Janeiro: Lucerna, 2005. p. 11-27.

CHONG, Dennis; DRUCKMAN, James N. A Theory of Framing and Opinion Formation in Competitive Elite Environments. Journal of Communication, v. 57, n. 1, p. 99-118, mar. 2007.

CRESPI, Irving. El proceso de opinión pública. Barcelona: Ariel Comunicación, 2000.

DA VIÁ, Sarah Chucid. Opinião Pública: teécnica de formação e problemas de controle. São Paulo: Loyola, 1983.

EDWARDS, George C. Presidential influence in Congress. San Francisco: W. H. Freeman, 1980.

EDWARDS, George C.; GALLUP, Alec. Presidential approval: a sourcebook. Baltimore, USA: Johns Hopkins University Press, 1990.

EMEDIATO, Wander. A construção da Opinião Pública na Mídia. Belo Horizonte: FALE/UFMG, 2013.

ERIKSON, Robert S.; MACKUEN, Michael B.; STIMSON, James A. The macro polity. Cambridge: Cambridge University Press, 2002.

FIORINA, Morris. Retrospective voting in American national elections. New Haven: Yale University Press, 1981.

GALSTON, William A. If political fragmentation is the problem, is the Internet the solution. ANDERSON, David M.; CORNFIELD, Michael. The civic web: online politics and democratic values. Oxford: Rowman \& Littlefield Publishers, 2003. p. 35-44.

GOODHART, Charles A.; BHANSALI, Rajendra. Political economy. Political Studies, v. 18, n. 1, p. 43-106, mar. 1970.

GUREVITCH, Michael; BLUMLER, Jay. The Crisis of Public Communication. London: Routledge, 2002.

IYENGAR, Shanto; KINDER, Donald R. News that matters: television and American opinion. Chicago: University of Chicago Press, 2010.

IYENGAR, Shanto; PETERS, Mark; KINDER, Donald. Experimental demonstrations of the "notso-minimal" consequences of television news programs. American Political Science Review, v. 76, n. 4, p. 848-858, 1982. 
JOHNSON, Thomas; KAYE, Barbara. Using is believing: the influence of reliance on the credibility of online political information among politically interested Internet users. Journalism e Mass Communication Quarterly, v. 77, n. 4, p. 865-879, 2000.

KINDER, Donald R. Communication and politics in the age of information. In: SEARS, David O. et al. (Eds.). Oxford handbook of political psychology. Oxford: Oxford University Press, 2003. p. 357393.

KIOUSIS, Spiro. Public trust or mistrust? Perceptions of media credibility in the information age. Mass Communication e Society, v. 4, n. 4, p. 381-403, 2001.

KRAMER, Gerald H. Short-term fluctuations in US voting behavior, 1896-1964. American Political Science Review, v. 65, n. 1, p. 131-143, 1971.

LIPPMANN, Walter. Public Opinion. New York: Free Press, 1965.

LONG, Norton E. The local community as an ecology of games. American Journal of Sociology, v. 64, n. 3, p. 251-261, nov. 1958.

LODGE, Milton; TABER, Charles S. Three steps toward a theory of motivated political reasoning. In: LUPIA, Arthur; McCUBBINS, Mathew D.; POPKIN, Samuel L. (Eds). Elements of reason: cognition, choice, and the bounds of rationality. New York: Cambridge University Press, 2000. p. 183-213.

LODGE, Milton; TABER, Charles S. The automaticity of affect for political leaders, groups, and issues: an experimental test of the hot cognition hypothesis. Political Psychology, v. 26, n. 3, p. 455482, 2005.

LODGE, Milton; MCGRAW, Kathleen; STROH, Patrick. An impression-driven model of candidate evaluation. The American Political Science Review, v. 83, n. 2, p. 399-419, 1989.

MCCOMBS, Maxwell E.; SHAW, Donald L. The Agenda-Setting Function of Mass Media. Public Opinion Quarterly, v. 36, n. 2, p. 176-187, Summer 1972.

MCQUAIL, Denis. Introducción a la teoría de la comunicación de masas. México: Paidós, 1996.

MUELLER, John E. Presidential popularity from Truman to Johnson. The American Political Science Review, v. 64, n. 1, p. 18-34, 1970.

MUNDIM, Pedro. Cientistas políticos, comunicólogos e o papel da mídia nas teorias da decisão do voto. Revista Política Hoje, v. 19, n. 2, p. 338-364, 2010.

MUNDIM, Pedro. Cobertura da imprensa e eleiçóes presidenciais de 2006: efeitos realmente limitados? Revista Brasileira de Ciências Sociais, v. 29, p. 91-107, 2014.

MUTZ, Diana C. Mass media and the depoliticization of personal experience. American Journal of Political Science, v. 36, n. 2, p. 483-508, 1992.

NANNESTAD, Peter; PALDAM, Martin. The VP-function: A survey of the literature on vote and popularity functions after 25 years. Public Choice, v. 79, n. 3-4, p. 213-245, 1994.

NEUSTADT, Richard E. Presidential power: the politics of leadership from FDR to Carter. New York: Wiley, 1980.

PARK, Robert E. The City: Suggestions for the Study of Human Nature in the Urban Environment. Chicago: University of Chicago Press, 1925.

PORTO, Mauro Pereira. Televisão e política no Brasil: a Rede Globo e as interpretaçóes da audiência. Rio de Janeiro: E-papers, 2007.

PRIOR, Markus. News vs. entertainment: How increasing media choice widens gaps in political knowledge and turnout. American Journal of Political Science, v. 49, n. 3, 2005. 
PRIOR, Markus. Post-broadcast democracy: how media choice increases inequality in political involvement and polarizes elections. New York: Cambridge University Press, 2007.

RIVERS, Douglas; ROSE, Nancy L. Passing the president's program: public opinion and presidential influence in Congress. American Journal of Political Science, v. 29, n. 2, p. 183-196, 1985.

SAMPAIO, Thiago. Popularidade presidencial: análise dos microfundamentos do suporte público da presidente Dilma Rousseff. 2014. 256f. Tese (Doutorado em Ciência Política) - Departamento de Ciência Política, Universidade Federal de Minas Gerais, Belo Horizonte, 2014.

STROUD, Natalie Jomini. Media use and political predispositions: Revisiting the concept of selective exposure. Political Behavior, v. 30, n. 3, p. 341-366, 2008.

SUNSTEIN, Cass R. Republic.Com. Princeton: Princeton University Press, 2001.

SUNSTEIN, Cass R. Republic.com 2.0. Princeton: Princeton University Press, 2009.

TELLES, Helcimara; SAMPAIO, Thiago; BAPTISTA, Érica. Estudo brasileiro de mídia: avaliação de governo e o consumo de mídia. In: IX Encontro da ABCP, Brasília, 2014.

TELLES, Helcimara de Souza. Corrupção, Legitimidade Democrática e Protestos: o Boom da Direita na Política Nacional? Interesse Nacional, v. 8, p. 28-46, 2015. Disponível em: $<$ http://interessenacional.com/.> Acesso em: 04 dez. 2015.

WEAVER, David H. Thoughts on Agenda Setting. Framing, and priming. Journal of Communication, n. 57, n. 1, p. 142-147, mar. 2007. 